Friedrich, V., Hofmann, S. \& Bauer, G. (2015). Strategies of Active Dissemination of Workplace Health

Promotion. In: International Journal of Workplace Health Management (8/1) (pp 3-14).

\title{
Strategies of Active Dissemination of Workplace Health Promotion
}

\section{Abstract}

Purpose: A growing body of literature provides evidence for the efficacy of workplace health promotion (WHP).

However, little is known about effective dissemination strategies for WHP interventions. In this article, we describe how a WHP agency in Zurich, Switzerland, used bulk mailings, information events, telephone marketing and free initial consultations for the large-scale geographic marketing of WHP services, with a focus on tobacco prevention (TP).

Methodology: To analyze the number of companies responding positively to solicitation, examine the predictors of positive responses, and explore the reasons for negative responses, we used both quantitative (e.g. a standardized questionnaire) and qualitative (telephone interviews) methods.

Findings: The results show that except for telephone marketing (69\%), the success rates of dissemination activities were very low (3-9\%). Predictors for a positive response were institutionalisation of WHP, the representative's personal concern about TP, and problems with environmental tobacco smoke within the company. The most prominent reason for a negative response was that the companies had already implemented TP measures by themselves and needed no further external support.

Practical implications: It is suggested that TP was the wrong emphasis for a WHP program to be disseminated at that particular time, because a law on protection from passive smoking was introduced in Switzerland shortly afterwards.

Value: The study examines dissemination strategies under real-life consulting conditions. It builds on a large sample of companies and uses both quantitative and qualitative research methods. It reports specific numbers and success rates of marketing activities and thereby contributes to the knowledge about an important issue for intervention planning in the field of WHP.

Keywords: Health promotion; workplace health; health marketing; tobacco prevention Word count: 4'741 (including title, abstract and references) 


\section{INTRODUCTION}

Workplace health promotion (WHP) covers all the efforts of employers, employees, and society as a whole to improve health at work (ENWHP, 2007). A growing body of literature reviews provides evidence for the efficacy of WHP (De Greef and Van den Broek, 2008; Egan et al., 2007; Engbers et al., 2005; Goldgruber and Ahrens, 2010; Saksvik et al., 2002; Shain and Kramer, 2004). However, if any kind of WHP intervention is ultimately to have a public health impact, it must be disseminated among and adopted by companies (Glasgow et al., 1999). In Switzerland, while safety at work is regulated by law, WHP in its broadest sense is voluntary for companies (Rückstuhl, 2011) and competes with a multitude of other management tasks. This might explain the limited prevalence of WHP in Switzerland - as in many other European countries (Bauer and Jenny, 2010; Bauer et al., 2002; Meggeneder et al., 2005). Dissemination therefore becomes a major issue. However, as only few studies report on dissemination strategies and their success (Bull et al., 2003; Maibach et al., 2006; Shojania and Grimshaw, 2005), little is known about how best to structure a targeted marketing approach to WHP and about predictive factors for a positive response to its solicitation. This study therefore focuses on methods for the large-scale geographical marketing of WHP services.

In agreement with Maibach et al. (2006), we “use the term dissemination to mean a series of planned activities intended to encourage and enable adoption and implementation of proven approaches” (p. 2). Accordingly, the present article describes a series of activities, applied by a WHP consulting agency in Zurich, Switzerland, intended to encourage companies in the Canton of Zurich to implement a comprehensive WHP program with a focus on tobacco prevention. The dissemination activities included bulk mailings, information events, telephone marketing, and free initial consultations; the evaluation concentrates on the question of how many and which companies respond to the different dissemination activities. In the following sections, we describe the study setting and the rationale for the WHP 
program, the dissemination activities, their evaluation, and the results. Finally, we discuss the success and failure of the dissemination activities with a view to future WHP dissemination.

\section{Study setting and rationale for the WHP program}

We established a research-practice partnership that allowed us to study dissemination in a naturally occurring service delivery situation in which WHP consultants offer WHP services

to customers. Marketing strategies were developed and implemented between 2007 and 2009 by consultants with the aim of sensitizing for and providing information about worksite health, advertising their services, and potentially recruiting companies for chargeable WHP intervention projects.

The consulting agency’s standard offer includes a modular web-based WHP toolbox which contains practical guidelines as well as training and presentation material for various health topics (see further details in Bauer and Jenny, 2007). As a new federal law on protection against passive smoking was pending (and was introduced in May 2010), companies were faced with the necessity of addressing the issue of smoke-free regulations. The consulting agency therefore decided to integrate tobacco prevention into its offer. The program to be disseminated included a behavioral (smoking cessation courses) and a conditional component (introducing non-smoking policies) to be adapted to the conditions prevailing within the company. The program integrated TP into a comprehensive approach to WHP: the consultants were ready to also approch health topics other than TP and establish for example health circles in the companies, when appropriate. The rationale for comprehensive approaches to WHP has been widely discussed (see for example Stokols, 1996; Weiner et al., 2009). In this study, the WHP consultants chose a comprehensive approach in order to consider working conditions and job-related health determinants as factors that can cause and maintain nicotine dependency (e.g. stress). But also to approach problems linked to cessation (e.g. body weight 
and diet) and to the introduction of smoke-free worksites (e.g. corporate communications, team climate) within the more general context of work, health and organizational development.

\section{DISSEMINATION ACTIVITIES AND EVALUATION QUESTIONS}

The dissemination activities started by sending a bulk-mailed information brochure to companies in the Canton of Zurich and continued with more intensive follow-up activities targeted to sub-groups of companies. The selection of sub-groups was based on the response to a bulk-mailed questionnaire and on practical considerations linked to the resources of the consulting agency. Table 1 gives an overview of the dissemination activities, evaluation questions and associated evaluation methods. In the following paragraphs, we describe these activities, all of which were free of charge for the companies and present the questions that are to be answered with regard to each activity.

(Table 1 about here)

\section{Bulk mailings}

The WHP consultants produced a brochure as a basis for raising awareness of WHP and TP issues and in order to promote their services. It explains the benefits of worksite TP and WHP, emphasizes the advantages of integrating TP into a comprehensive WHP approach, shows how to proceed in practice, and gives information about the consulting agency's offers. The brochure was bulk-mailed to all companies in the Canton of Zurich, Switzerland, with more than 20 employees (4’706) and addressed to human resources or occupational health managers. The questions to be answered with respect to the bulk mailing are: How many companies express interest in the agency's services? What kinds of services are requested? 
And what are the reasons for a lack of interest? Additionally, we explored which of the following variables predict interest in services: institutionalisation of WHP within the organisation, problems relating to environmental tobacco smoke (ETS), perceived advantages of and personal concern for TP, company size (20-49 employees, 50-250 employees, >250 employees) and industry type (building, hospitality, health and welfare, other). Data were except for company size and industry type - collected via a written questionnaire that was appended to the mailing (see Methods section).

\section{Information events}

The next step in the dissemination process was to arrange information events to verbally present the idea of integrating TP into a comprehensive WHP approach, to inform the participants about the consulting agency's WHP services and about the services of the TP agencies who acted as project partners, and about current and pending legal regulations concerning tobacco consumption at the workplace. The process of introducing a smoke-free rule in a bank was reported as a model of good practice. Not all companies were invited to the event, as the consulting agency only had the capacity to host 150 guests for three planned events. The consultants therefore randomly selected and invited 950 companies that had responded to the bulk-mailed questionnaire, as they expected an attendance rate of approximately 15\%. The questions to be answered with respect to the information events are: How many companies participate in the events? What are the predictive factors (see above) for participation? And what are the reasons for non-participation?

\section{Telephone marketing}

To approach the companies more directly, the WHP professionals ran an intensive telephone marketing campaign. Again, as the consulting agency’s resources were limited, the 
consultants took the group of 950 responders already noted as a basis. Within this group, they contacted all 36 companies with more than 250 employees (because of the large number of employees potentially reachable via each company contact), all 43 companies that had expressed interest in a personal consultation in the initial questionnaire, and a random sample of the companies that had expressed interest in implementing smoke-free worksites (54 companies). With only a few exceptions, they managed to contact the source who had completed the survey. The aim of the telephone marketing campaign was to inform the respondents about WHP services and arrange an initial personal consultation for large and medium-sized enterprises and a telephone consultation for small ones. The questions to be answered with regard to the telephone marketing campaign are: How many companies are recruited for an initial consultation, and what are the predictive factors for recruitment success?

\section{Initial consultation}

At the initial consultations, the WHP professionals analyzed the situation (problems, existing WHP measures etc.) in the organization by talking to company representatives (generally the recipient of the phone call). The aim of these consultations, each lasting about 30 minutes, was to impart basic information about work and health, about introducing WHP and TP measures customized to the situation in the respective company, and to recruit companies for in-depth WHP or TP consultancy projects. Whereas all dissemination activities were free of charge for the companies, the consultancy projects were at the companies' own expense. The questions to be answered with regard to the initial consultations are: How many companies are recruited for consultancy projects? How many companies implement WHP and/or TP measures by themselves as a result of the consultation? 


\section{DATA COLLECTION AND ANALYSES}

To evaluate the results of the bulk mailings, we used a questionnaire that was appended to the bulk-mailed brochure. The questionnaire, which is also described in Friedrich et al. (2009), assessed the following six variables: 1) Interest in using the consulting agency's services ("I want to learn more about the introduction of smoke-free worksites"; "I want to learn more about workplace health promotion”; "I wish to receive a free personal consultation”; "I wish to attend a free information event”; yes/no answer in each case). For the composite variable 'interest in any of the consulting agency's services' any yes-answer to one of these questions was counted only once (interest in any services $=1$, no interest in any service $=0$ ). 2 ) Reasons for not being interested ("I am not interested in using any services”, with answer options to specify reasons). 3) Institutionalisation of WHP (three statements concerning funds allocated to health promotion, WHP as task of a person or organizational unit, and systematic analysis of health figures, cf. Bauer et al., 2002). 4) Problems relating to environmental tobacco smoke (ETS) (two statements referring to employees being exposed to ETS and complaints about ETS, cf. Biener et al., 1999). 5) Perceived advantages of TP (eight items dealing with pros and cons - health and economic benefits, rejection by employees, investments - of smokefree workplaces and smoking cessation courses from the management's perspective, Bauer and Jenny, 2007; McMahon et al., 2002). 6) Personal concern about TP (“'Smoking is a private matter and none of the company's business", "I am personally concerned about TP in our company"). The items concerning the institutionalisation of WHP, ETS-related problems, perceived advantages and personal concern used a 5-point scale ( 1 = disagree, 5 = agree); scale means were computed for each variable. Information about company size (number of employees) and industry type was obtained from the Federal Statistics Office.

To evaluate the results of the information events, three methods were used: Data on event participation were recorded in a customer database $($ participation $=1$, non-participation $=0$ ), from which it was possible to infer how many and which companies participated; data on 
predictive factors for event participation were taken from the bulk-mailed questionnaire; and the reasons for non-participation were explored using a qualitative approach (telephone interviews). For these interviews, a number of companies (11) were randomly selected from those that had expressed interest in but did not attend the event; the interviews were conducted with the person who had completed the survey.

To analyze the success of the telephone marketing campaign, the WHP consultants logged all phone calls and their results in the customer database; data on predictive factors for recruitment success were taken from the bulk-mailed questionnaire.

Participation in initial consultation was coded as ' 1 ' in the customer database (nonparticipation $=0$ ). To evaluate the outcomes of the initial consultations, the consultants recorded all consultations and their results in the customer database. To explore whether the counselees implemented WHP or TP measures by themselves, telephone interviews were conducted approximately three months after the consultation. The interviews were conducted with a randomly selected subsample (27) of the counselees who had not been recruited for chargeable consultancy projects; the individuals who had participated in the consultation were interviewed.

Data were analyzed by means of descriptive statistics (number of positive responses to dissemination activities) and logistic regressions (predictive factors for a positive response) using SPSS version 18.0. For the regression analyses, we first analyzed bivariate relationships by testing each predictor variable's predictive power for the respective outcome variable, and then entered significant $(\alpha<.05)$ variables simultaneously into conditional regression analyses. The interview protocols were analyzed by means of content analysis.

\section{RESULTS}

Table 2 shows the number of companies contacted, the number of companies giving a positive response, and the success rate for each dissemination activity. Information about the 
characteristics of responding companies in terms of company size and branches can be obtained from Table 4 (left column).

(Table 2 about here)

\section{Bulk mailings}

Of the 4'706 questionnaires, 1'648 were returned (response rate 36.5\%), and 1'627 could be analyzed (those with too many missing values, or those that were obviously not seriously completed were not analyzed). A total of 441 companies expressed interest in any of the consulting agency's services (27\%). Of these, 114 (25.4\%) were interested in learning more about smoke-free worksites; 324 (72.2\%) wanted information about workplace health promotion; 84 (18.7\%) wished to have a personal consultation, and 152 (34.4\%) wished to attend an information event. The companies that were not interested in any services (1'186) most frequently mentioned the following reasons: they had already implemented TP measures; it was not the right moment; the company would not provide resources for this topic; there was no time for such a project (see Table 3).

(Table 3 about here)

To explore the predictive factors for interest in services, logistic regressions were performed, with interest in any of the agency's services as the outcome variable. The results indicate that institutionalisation of WHP, problems with environmental tobacco smoke (ETS), the perceived advantages of TP and the representative’s personal concern about TP are associated with interest in services (Table 4). WHP institutionalisation, ETS problems, and personal concern remain significant predictors when these factors were simultaneously entered. 
(Table 4 about here)

\section{Information events}

Of 947 invitees, 29 (3\%) participated in one of the first two information events. A third session was cancelled because of the low registration rate (only seven companies registered). The results of regression analyses (see Table 4) indicate that companies from the health and welfare sector were more likely to participate; WHP institutionalisation and personal concern are also predictors for event participation. Those predictors remain significant in the conditional analysis. The reasons for non-participation, as explored in telephone interviews, were: the companies had already found solutions (e.g. implemented smoking regulations) by themselves and needed no further information (mentioned eight times); they had had no time to participate (mentioned three times).

\section{Telephone marketing}

A total of 133 companies were contacted by telephone. Of these, 54 were willing to accept an initial consultation by telephone, and 38 companies agreed to a face-to-face consultation (participation rate: 69.2\%). Regression analyses indicate that problems relating to environmental tobacco smoke predict participation in the initial consultation (Table 4).

\section{Initial consultations}

Of the 92 companies that had received initial consultations, four were recruited for chargeable consultancy projects (success rate 4.3\%). Records in the customer database show that the other companies (54) would get in contact with the consultants as needed; 18 asked to be contacted again at a later date; 16 companies saw no further need for support. The qualitative 
interviews with a subsample of 27 counselees indicate that five companies (18\%) had started a WHP/TP intervention program by themselves as a result of the consultation; three (11\%) said they planned an intervention, and 19 (70\%) stated they had not initiated such a project and did not plan to do so.

\section{DISCUSSION}

In this article, we illustrated how a WHP consulting agency proceeded to disseminate its services. We analyzed how many companies responded positively to the various dissemination activities, examined the predictors for a positive response, and explored the reasons for a negative response and non-participation, respectively. The results show that except for telephone marketing, the success rates of the dissemination activities were very low. An information session was suspended because of a lack of interest, and in spite of initially contacting over 4’000 companies, only four were eventually interested in a paid consulting service. This failure is probably due to tobacco prevention being the wrong emphasis for a program to be disseminated among worksites in the Canton of Zurich at that particular time: in anticipation of the federal law on protection from passive smoking, a substantial proportion of companies had already implemented smoke-free regulations (see Table 3), and some might also have awaited the law before implementing a regulation. As also illustrated by the results of the initial questionnaire, TP was not a primary workplace interest that triggered demand for an external consultation. All in all, it is likely that in the present case the problem lay in the content, rather than the marketing design, although tobacco prevention was communicated and offered within a comprehensive WHP approach. However, to know what a "good" success rate would be, and to put the results of this study in context, it would be helpful to know the success rates of comparable approaches to disseminating WHP. Although some studies do focus on WPH dissemination, it is difficult to find comparable figures: sometimes it is not explained how the companies were recruited 
(Hawkins et al., 2009); other studies report participation rates of employees rather than of organizations (Bull et al., 2003; You et al., 2011); or dissemination takes place among companies with which the consultants have already established a relationship (Harris et al., 2008). Also, results obtained in the USA are not easily comparable with those in Switzerland, where the organizational support of health programs has no fiscal and actuarial benefits for employers.

A comparison of the different dissemination activities used in this study shows that the success rates of telephone marketing were higher than those of the other dissemination activities, and were in fact satisfactory. However, it has to be kept in mind that these activities were designed to yield different outcomes: participating in a 30 minute counseling interview at their own office or on the telephone (which was the intended outcome of the telephone marketing campaign) is less costly for the companies than attending the information event (which was held in Zurich and lasted approximately two hours). Consequently, the intended outcome of the telephone marketing campaign was relatively easier to achieve. Moreover, due to the successive approach and the selection of sub-groups, the groups of companies that were approached with the different dissemination activities are not comparable.

As regards the predictors for a positive response, the results indicate that the representative's personal concern for TP and institutionalisation of WHP within the company predicts interest in WHP services and participation in information events. These findings are in line with many other results from health promotion studies: it is easier to reach those who are already aware of the issue, and who are willing and have the resources to deal with it. This is a problem, because underprivileged groups of employees remain disadvantaged and have less chance of benefiting from WHP. Future studies should therefore investigate how to design dissemination activities to also reach those who are reluctant to use WHP innovations, i.e. the 'late majority’ and 'laggards’, to use Rogers’ (1995) labeling. However, the results of this study also show that health-related problems (in this case problems relating to passive 
smoking) within the companies predict interest in services and participation in an initial consultation; this indicates that the consultants succeeded in reaching companies in need of support.

The findings of this study have to be interpreted with due consideration of its limitations: as the study was run in an applied setting, the dissemination activities (including the definition of success criteria and the selection of groups of companies to be contacted) followed the logic of the consulting agency and were based on company characteristics as well as on practical considerations; a controlled design was not applied. Second, the data collected via the initial questionnaire stem from a self-selected sample. Only one representative provided information about the situation in the company, and the characteristics of the non-responders to the questionnaire were not researched. Third, the approach taken to assess the reasons for non-participation in information events and the results of the initial consultations via telephone interviews was rather opportunistic, as only a small number of companies (11 and 27 respectively) were interviewed for reasons of cost-efficiency.

The study also has some strengths. Instead of researchers designing and implementing the dissemination activities, as is commonly the case (Bull et al., 2003), it was conducted in an applied setting in "a close partnership between researchers and a disseminating organization that takes ownership of the dissemination process” (Harris et al., 2012). It therefore examines dissemination strategies under real-life consulting conditions. Second, the study built on a large sample of companies. Third, both quantitative and qualitative research methods were combined. Finally, as some conceptual papers deal with WHP dissemination but few studies report specific numbers and success rates, this study - despite its limitations - contributes to closing the knowledge gap concerning this important issue for WHP intervention planning. To conclude, our findings have some practical implications for WHP consultants who operate in a setting comparable to the one of this study: It is reasonable to start with a survey of the needs, interests and health related problems of companies. The thematic focus of 
dissemination activities and interventions should then be tailored accordingly, taking into account societal, legal, technological etc. developments. As a second step, it seems promising to directly start with telephone marketing; especially those companies should be contacted who report health related problems. To be able to respond to the different needs of the companies, it seems advisabe to prepare a modular system of interventions, not only in terms of different health topics, but also in terms of the intensity of external support (which should be high when there is no one responsible for and knowledgeable of WHP within the company), and in terms of intervention scope (low-threshold services are needed when budgets are restricted or when the topic of WHP is very new).

With regard to research, studying dissemination processes in naturally occurring service delivery situations is not always easily manageable and often does not allow for "strong" study designs. However, as more studies report on the practice of WHP dissemination in different contexts, a clearer picture will emerge of which strategies work for which target group under what conditions. 


\section{References}

Bauer, G. and Jenny, G. (2010) Anspruch und Wirklichkeit: Zum aktuellen Stand der betrieblichen Gesundheitsförderung. In G. Faller (Ed.), Lehrbuch Betriebliche Gesundheitsförderung. Bern: Hans Huber, pp. 48-56.

Bauer, G., Schmid, M., Zellweger, U. and Krueger, H. (2002) Betriebliches Gesundheitsmanagement 2001 - Entwicklungsstand in Schweizer Dienstleistungsunternehmen. Zurich: Institut für Sozialund Präventivmedizin der Universität Zürich / Institut für Hygiene und Arbeitsphysiologie ETH Zurich.

Bauer, G. and Jenny, G. (2007) Develpoment, implementation and dissemination of occupational health management (OHM): Putting salutogenesis into practice. In S. McIntyre and J. Houdmondt (Eds.), Occupational Healh Psychology. European Perspectives on Research, Education and Practice. Castelo da Maia: ISMAI, pp. 219-50.

Biener, L., Glanz, K., McLerran, D., Sorensen, G., Thompson, B., Basen-Engquist, K. et al. (1999) Impact of the Working Well Trial on the worksite smoking and nutrition environment. Health Education and Behavior, 26(4), 478-494.

Bull, S., Gillette, C., Glasgow, R. and Estabrooks, P. (2003) Work site health promotion research: To what extend can we generalize the results and what is needed to translate research to practice? Health Education and Behavior, 30(5), 537-549.

De Greef, M. and Van den Broek, K. (2008) Making the case for workplace health promotion. Analysis of the effects of WHP. Brussel: ENWHP.

Egan, M., Bambra, C., Thomas, S., Petticrew, M., Whitehead, M. and Thomson, H. (2007) The psychosocial and health effects of workplace reorganisation. A systematic review of organisational-level interventions that aim to increase employee control. Journal of Epidemiology and Community Health, 61(11): 945-54.

Engbers, L., van Poppel, M., Chin A Paw, M. and van Mechelen, W. (2005) Worksite health promotion programs with environmental changes. A systematic review. American Journal of Preventive Medicine, 29(1): 61-70.

ENWHP (2007) Luxembourg Declaration on workplace health promotion in the European Union. http://www.enwhp.org/fileadmin/rs-dokumente/dateien/Luxembourg_Declaration.pdf (last accessed 22. June 2012).

Friedrich, V., Brügger, A. and Bauer, G. (2009) Worksite tobacco prevention in the canton of Zurich: Stages of change, predictors and outcome. International Journal of Public Health, 54(6): 42738.

Glasgow, R., Vogt, T. and Boles, S. (1999) Evaluating the public health impact of health promotion interventions: the RE-AIM framework. American Journal of Public Health, 89(9): 1322-27.

Goldgruber, J. and Ahrens, D. (2010) Effectiveness of workplace health promotion and primary prevention interventions: A review. Journal of Public Health, 18: 75-88.

Harris, J., Cheadle, A., Hannon, P., Lichiello, P., Forehand, M., Mahoney, E. et al. (2012) A framework for disseminating evidence-based health promotion practices. Preventing Chronic Disease, 9: E22.

Harris, J., Cross, J., Hannon, P., Mahoney, E., Ross-Viles, S. and Kuniyuki, A. (2008) Employer adoption of evidence-based chronic disease prevention practices: A pilot study. Preventing Chronic Disease, 5(3): A92.

Hawkins, C., O'Garro, M. and Wimsett, K. (2009) Engaging employers to develop healthy workplaces: The WorkWell initiative of steps to a healthier Washington in Thurston County. Preventing Chronic Disease, 6(2): A61.

Maibach, E., Van Duyn, M. and Bloodgood, B. (2006) A marketing perspective on disseminating 
evidence-based approaches to disease prevention and health promotion. Preventing Chronic Disease, 3(3): A97.

McMahon, A., Kelleher, C., Helly, G. and Duffy, E. (2002) Evaluation of a workplace carciovascular health promotion programme in the Republic of Ireland. Health Promotion International, 17(4), 297-308.

Meggeneder, O., Pelster, K. and Sochert, R. (2005) Betriebliche Gesundheitsförderung in kleinen und mittleren Unternehmen. Bern: Huber.

Rogers, E. M. (1995) Diffusion of innovations (4th ed.). New York: Free Press.

Rückstuhl, B. (2011) Gesundheitsförderung in der Schweiz. Köln: BZgA. http://www.bzga.de/leitbegriffe/?uid=a7c525cc43be15b4dcc7f9b6defcfb3c\&id=angebote\&idx= 173 (last accessed 22. June 2012).

Saksvik, P., Nytrø, K., Dahl-Jørgensen, C. and Mikkelsen, A. (2002) A process evaluation of individual and organizational occupational health interventions. Work \& Stress, 16: 37-57.

Shain, M. and Kramer, D. (2004) Health promotion in the workplace: Framing the concept; reviewing the evidence. Journal of Occupational and Environmental Medicine, 61: 643-48.

Shojania, K. and Grimshaw, J. (2005) Implementing evidence: evidence-based quality improvement: The state of the science. Health Affairs, 24(1): 138-50.

Stokols, D. (1996). Translating social ecological theory into guidelines for community health promotion. American Journal of Health Promotion, 10, 282-298.

Weiner, B., Lewis, M. and Linnan, L. (2009) Using organization theory to understand the determinants of effective implementation of worksite health promotion programs. Health Education Research, 24(2), 292-305.

You, W., Almeida, F., Zoellner, J., Hill, J., Pinard, C., Allen, K. et al. (2011) Who participates in internet-based worksite weight loss programs? BMC Public Health, 11: 709. 